\title{
Isolated Diaphyseal Fractures of the Radius in Skeletally Immature Patients
}

\author{
Thierry G. Guitton • Niek C. Van Dijk • \\ Ernst L. Raaymakers • David Ring
}

Received: 23 July 2009 / Accepted: 9 October 2009/Published online: 27 October 2009

(C) American Association for Hand Surgery 2009

\begin{abstract}
Diaphyseal radius fractures without associated ulna fracture or radioulnar dislocation (isolated fracture of the radius) are recognized in adults but are rarely described in skeletally immature patients. A search of our database (1974-2002) identified 17 pediatric patients that had an isolated fracture of the radius. Among the 13 patients with at least 1 year follow-up, ten were treated with manipulative reduction and immobilization in an above elbow cast and three had initial operative treatment with plate and screw fixation. These 13 patients were evaluated for an average of 18 months (range, 12 to 45 months) after injury using the system of Price and colleagues. The incidence of isolated diaphyseal radius fractures in skeletally immature patients was 0.56 per year in our database and represented $27 \%$ of the 63 patients with a diaphyseal forearm fracture. All 13 patients, with at least 1 year follow-up, regained full elbow flexion and extension and full forearm rotation. According to the classification system of Price, all 13 patients (100\%) had an excellent result. As in adults, isolated radius fractures seem to occur in children more frequently than previously appreciated. Treatment of isolated radius fractures in skeletally immature patients has a low complication rate, and excellent functional outcomes are the rule.
\end{abstract}

T. G. Guitton · D. Ring $(\bowtie)$

Harvard Medical School,

Orthopaedic Hand and Upper Extremity Service,

Massachusetts General Hospital,

Yawkey Center, Suite 2100, 55 Fruit Street,

Boston, MA 02114, USA

e-mail: dring@partners.org

N. C. Van Dijk • E. L. Raaymakers

Department of Orthopaedic Surgery,

Academic Medical Center Amsterdam,

Meibergdreef 9 ,

1100 Amsterdam, The Netherlands
Keywords Radius fracture · Skeletally immature · Diaphyseal

\section{Introduction}

Fractures of the forearm are common orthopedic injuries in children $[6,19,21,35]$ accounting for $30 \%$ to $50 \%$ of all pediatric fractures $[2,15,18,38]$. About $18 \%$ of all forearm fractures occur in the shaft of the radius and the ulna $[1,4,9]$, and these diaphyseal fractures can be divided into three categories: plastic deformation, greenstick, and complete diaphyseal fractures. In the forearm, either both bones or one bone and one radioulnar joint (Monteggia and Galeazzi lesions) are typically injured, and isolated fractures are relatively uncommon [36]. Therefore, single-bone fractures should always raise suspicion regarding additional injury to the proximal or distal radioulnar joint $[24,25,30]$.

In adults, the concept of an isolated ulna fracture (the socalled "nightstick" fracture) is well-accepted, but the concept of an isolated radius fracture is traditionally less well-accepted, and textbooks usually describe Galeazzi fractures alone $[5,16,32]$ or mention isolated radius fractures, but there is a caution that most will have an associated injury to either the proximal or distal radioulnar joint [12, 23, 33]. More recently, however, several papers have described that diaphyseal radius fractures without associated radioulnar dislocation occur more frequently than previously recognized and appear to be more common than Galeazzi lesions [31, 33].

Most reports of diaphyseal forearm fractures in children address treatment techniques of fractures of both the radius and ulna. To our knowledge, there have been no reports of isolated diaphyseal radius fractures in children specifically, although a few patients with isolated radius fractures have 
been included in larger series of diaphyseal forearm fractures in general $[17,20,22,28,29,34,39-42]$. A few papers state that isolated dislocations of the DRUJ and Galeazzi fractures are unusual in children [3, 13, 24, 37] and the diagnosis can therefore be overlooked [8, 37].

This investigation describes the treatment and subsequent outcome of diaphyseal fractures of the radius without associated injury to the ulna or radioulnar joints (isolated radius fractures) in 17 skeletally immature patients.

\section{Materials and Methods}

All fractures at our institution were entered into a database organized according to the AO Comprehensive Classification of Fractures [26] between 1974 and 2002. A search of this database identified 17 consecutive skeletally immature patients that had a treatment of a Type 22-A2 diaphyseal fracture of the radius according to the $\mathrm{AO}$ comprehensive classification of fractures [26]. This represented $27 \%$ of the 63 skeletally immature patients with a diaphyseal forearm fracture in the database. The incidence of isolated radius fractures in skeletally immature patients was 0.56 at our institution during the study period. Patients were treated by an attending general orthopedic surgeon or a general trauma surgeon experienced in $\mathrm{AO}$ principles and techniques of internal fixation [26].

Using a protocol approved by our ethics committee, we reviewed the medical records of these 17 patients. We report the results of treatment in 13 patients that had at least 12 months follow-up available in the medical record.

Clinical outcome was graded with a scale used by Price et al. [27], which is based on the rating scales of Daruwalla [7] and Grace [11]. Patients were rated as excellent if there were no complaints with strenuous physical activity and less than $10^{\circ}$ loss of forearm rotation. A result was considered good if there were only mild complaints with strenuous physical activity or an $11^{\circ}$ to $30^{\circ}$ loss of forearm rotation or both. A result was considered fair if there were mild subjective complaints during daily activities or a $31^{\circ}$ to $-90^{\circ}$ loss of forearm rotation or both. All other results were considered poor.

Among all 17 patients in the cohort, there were 14 male and three female patients with an average age of 10 years (range, 1 to 18 years). Eight patients injured the left arm and nine patients injured the right arm. Limb dominance was not recorded. Patients were injured in a fall from a standing height in ten cases (four during sports), three in a bicycle accident, and four in a motor vehicle collision (one as pedestrian). Two patients had injuries of the ipsilateral upper extremity, including a distal humerus fracture and a humeral shaft fracture.

\section{Results}

Injury Characteristics

The isolated radius fractures were classified based on radiographs taken immediately after injury and intraoperative findings according to the Comprehensive Classification of Fractures [26] as Type A2.1 in 4, Type A2.2 in 11, and Type A2.3 in 2 cases, respectively (Figs. 1 and 2).
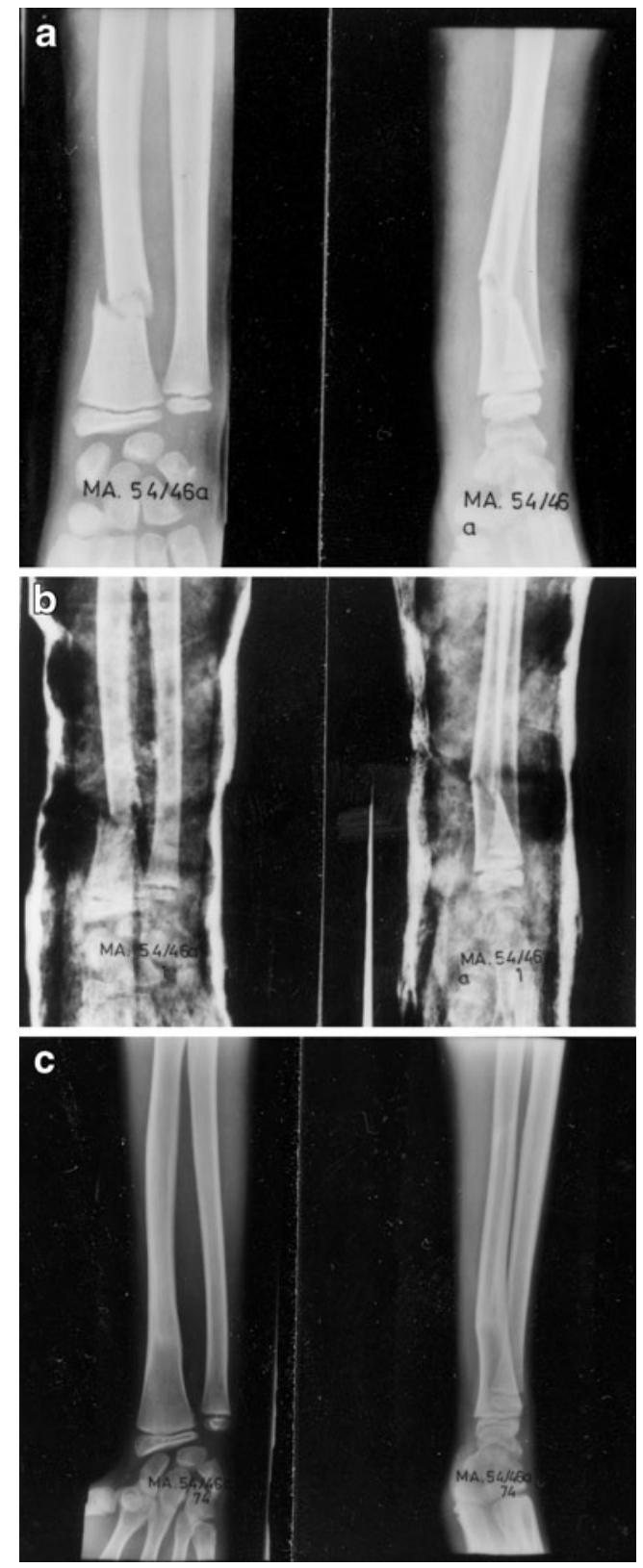

Figure 1 a Anteroposterior and lateral radiographs of a 10-year-old boy who fell at school and sustained an isolated fracture of the radial diaphysis. b Anteroposterior and lateral radiographs demonstrating cast immobilization. c Radiographs obtained 6 months after injury show solid healing of the fracture. 

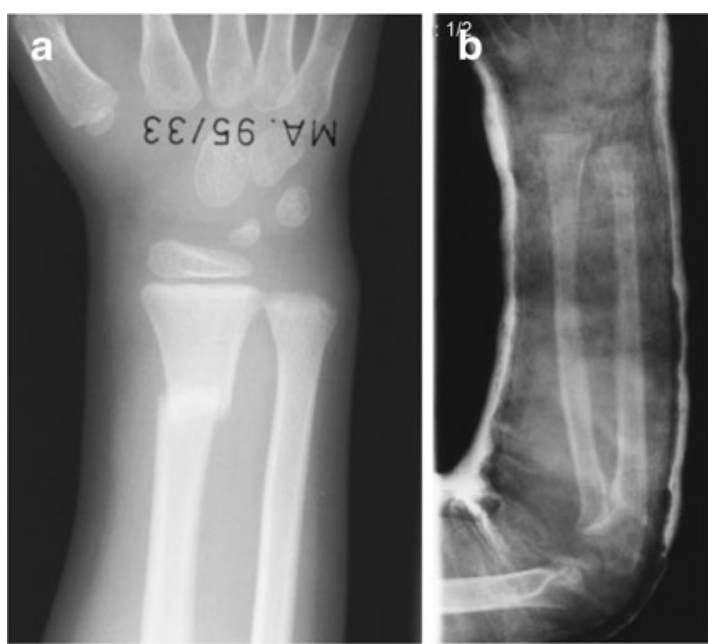

Figure 2 a Anteroposterior radiograph of a 5-year-old boy who fell at home sustaining an isolated fracture of the distal radial diaphysis. b Anterioposterior and lateral radiographs demonstrating treatment with
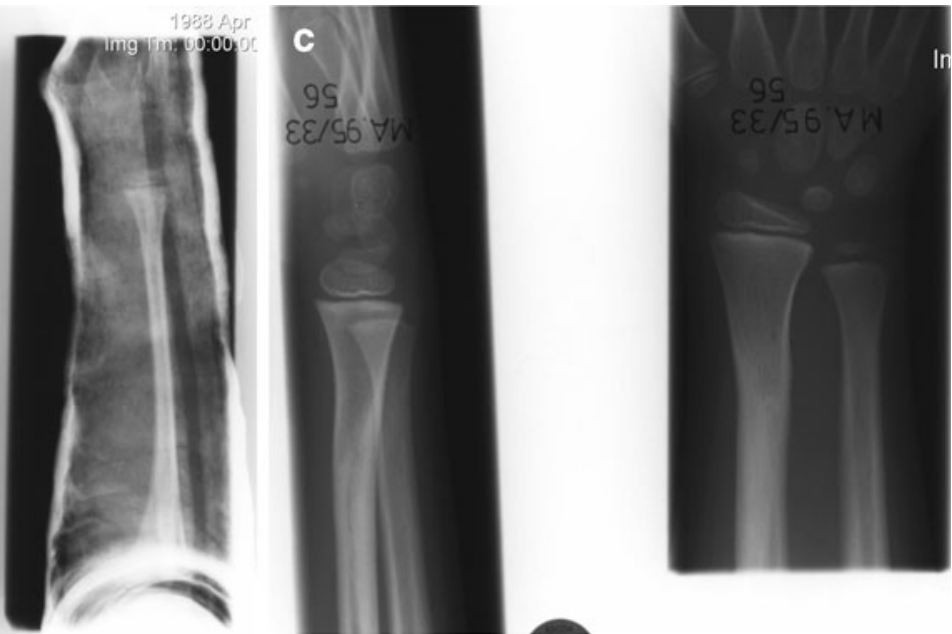

cast immobilization. c Radiographs taken nearly 1 year after injury show solid healing and some remodeling.

Final Result

At an average of 18 months (range, 12 to 45 months) after the injury, all 13 patients evaluated at least 1 year after injury had regained full elbow flexion and extension and full forearm rotation. According to the classification system of Price, all 13 patients $(100 \%)$ had an excellent result.

\section{Discussion}

The low incidence of isolated diaphyseal radius fractures in skeletally immature patients $(0.56$ per year at our institution during the study period) may explain why they are underrepresented in the literature. As in adults, we now recognize that skeletally immature patients can sustain an isolated fracture of the radius without additional fractures or dislocations. These findings should not encourage complacency but should rather increase vigilance regarding potential radioulnar injuries. In the absence of radioulnar injury, an isolated radius fracture may prove more straightforward to treat than a Galeazzi injury and may have a better prognosis.

Cast treatment is effective in most skeletally immature patients with isolated radius fractures, and surgery seemed to be used primarily in older patients and according to surgeon preference at our institution. The role of operative treatment remains unclear, but as with other diaphyseal forearm injuries in the skeletally immature, operative treatment should be more readily considered in patients nearing skeletal maturity. According to the literature, the following guidelines may be reasonable: angulation of up to $20^{\circ}$ is acceptable in children less than 8 years old, but no
One patient was felt to have inadequate alignment 2 weeks after manipulation and casting and was treated with open reduction and plate and screw fixation. One cast-treated patient sustained a refracture within 3 months that was treated in a cast. 
more than $10^{\circ}$ is acceptable in older children with less than 2 years of expected additional growth [7, 10, 14, 27].

Isolated radius fractures seem to occur in adults and children more frequently than previously appreciated. Based on our data, it seems possible for the radius to be fractured without dislocating the radioulnar joints or also fracturing the ulna. This small series shows that treatment of isolated radius fractures in skeletally immature patients has a low complication rate, and excellent functional outcomes are the rule.

Acknowledgments The authors wish to thank the AO Documentation Center in Davos, Switzerland and Dr. E.L.F.B. Raaymakers for managing the fracture database for the Departments of Orthopedic Surgery and General Surgery at the Academic Medical Center in Amsterdam, the Netherlands, over the last decades. All cases included in the study were identified through this database. We wish to thank the Departments of Surgery and Traumatology for their kind permission to use the data of their patients.

Disclosures One or more of the authors received funding from Wright Medical (DR), Stichting Wetenschappelijk Onderzoek Orthopaedisch Chirurgie (TG), VSB Fonds (TG), Acumed (DR), and Tornier (DR).

\section{References}

1. Armstrong PF, Joughlin VE, Clarke HM. Pediatric fractures of the forearm, wrist and hand. In: Green NESMF, editor. Skeletal trauma in children. Philadelphia: W.B. Sounders Company; 1998. p. 161-258.

2. Bailey DA, Wedge JH, McCulloch RG, et al. Epidemiology of fractures of the distal end of the radius in children as associated with growth. J Bone Joint Surg Am. 1989;71(8):1225-31.

3. Birch-Jenson A. Luxation of the distal radial-ulnar joint. Acta Chir Scand. 1951;101:312-7.

4. Blount W, Shaefer A, Johnson J. Fractures of the forearm in children. JAMA. 1942;120:111-16.

5. Carr A, Worloch P. Fractures and dislocations: principles of management. In: PH; GPSJW, editor. The forearm. London: Blackwell Sciences; 1996. p. 435-46.

6. Cheng JC, Shen WY. Limb fracture pattern in different pediatric age groups: a study of 3, 350 children. J Orthop Trauma. 1993;7 (1):15-22.

7. Daruwalla JS. A study of radioulnar movements following fractures of the forearm in children. Clin Orthop Relat Res. 1979;139:114-20.

8. de la Rosa LAP, Ibarra SM. Incidencia de las fracturas de Galeazzi en nioos. Acta Ortop, dica Mexicana. 2002;16(6):321-4.

9. Gandhi RK, Wilson P, Mason Brown JJ, et al. Spontaneous correction of deformity following fractures of the forearm in children. Br J Surg. 1962;50:5-10.

10. Gibbons CL, Woods DA, Pailthorpe C, et al. The management of isolated distal radius fractures in children. J Pediatr Orthop. 1994;14(2):207-10.

11. Grace TG, Eversmann WW Jr. Forearm fractures: treatment by rigid fixation with early motion. J Bone Joint Surg Am. 1980;62 (3):433-8.

12. Hattoma N, Rafai M, Zahar A, et al. Lesions of the distal radioulnar joint associated with isolated fractures of the radial shaft. Acta Orthop Belg. 2002;68(5):476-80.
13. Heiple K, Freehafer A. Van't Hof A. Isolated traumatic dislocation of the distal end of the ulna or distal radio-ulnar joint. J Bone Joint Surg Am. 1962;44A:1387-93.

14. Hogstrom H, Nilsson BE, Willner S. Correction with growth following diaphyseal forearm fracture. Acta Orthop Scand. 1976;47(3):299-303.

15. Jones IE, Cannan R, Goulding A. Distal forearm fractures in New Zealand children: annual rates in a geographically defined area. $\mathrm{N}$ Z Med J. 2000;113(1120):443-5.

16. Jupiter JB, Kellam JF. Diaphyseal fractures of the forearm. In: P. G. BBDJJBLAMT, editor. Skeletal trauma: fractures, dislocations and ligamentous injuries. 3rd ed. Philadelphia: Saunders; 2003. p. 1363-403

17. Kapoor V, Theruvil B, Edwards SE, et al. Flexible intramedullary nailing of displaced diaphyseal forearm fractures in children. Injury. 2005;36(10):1221-5.

18. Kramhoft M, Bodtker S. Epidemiology of distal forearm fractures in Danish children. Acta Orthop Scand. 1988;59(5):557-9.

19. Landin LA. Fracture patterns in children. Analysis of 8,682 fractures with special reference to incidence, etiology and secular changes in a Swedish urban population 1950-1979. Acta Orthop Scand Suppl. 1983;202:1-109.

20. Majed A, Baco AM. Nancy nail versus intramedullary wire fixation of paediatric forearm fractures. J Pediatr Orthop, B. 2007;16(2):129-32.

21. Mann DC, Rajmaira S. Distribution of physeal and nonphyseal fractures in 2, 650 long-bone fractures in children aged 0 16 years. J Pediatr Orthop. 1990;10(6):713-6.

22. Maric D, Petkovic L, Tomasevic V, et al. Osteosynthesis with Kirschner wires in the treatment of dislocation fractures of the forearm in children. Med Pregl. 2002;55(3-4):140-5.

23. Mestdagh H, Duquennoy A, Letendart J, et al. Long-term results in the treatment of fracture-dislocations of Galeazzi in adults. Report on twenty-nine cases. Ann Chir Main. 1983;2(2):125-33.

24. Mikic ZD. Galeazzi fracture-dislocations. J Bone Joint Surg Am. 1975;57(8):1071-80.

25. Moore TM, Klein JP, Patzakis MJ, et al. Results of compressionplating of closed Galeazzi fractures. J Bone Joint Surg Am. 1985;67(7):1015-21.

26. Müller ME, et al. The comprehensive classification of fractures of long bones. Berlin: Springer-Verlag; 1990.

27. Price CT, Scott DS, Kurzner ME, et al. Malunited forearm fractures in children. J Pediatr Orthop. 1990;10(6):705-12.

28. Pugh DM, Galpin RD, Carey TP. Intramedullary Steinmann pin fixation of forearm fractures in children. Long-term results. Clin Orthop Relat Res. 2000;376:39-48.

29. Qidwai SA. Treatment of diaphyseal forearm fractures in children by intramedullary Kirschner wires. J Trauma. 2001;50 (2):303-7.

30. Reckling FW. Unstable fracture-dislocations of the forearm (Monteggia and Galeazzi lesions). J Bone Joint Surg Am. 1982;64(6):857-63.

31. Rettig ME, Raskin KB. Galeazzi fracture-dislocation: a new treatment-oriented classification. J Hand Surg [Am]. 2001;26 (2):228-35.

32. Richards R. Fractures of the shafts of the radius and ulna. In: J.D.; BRWH, editor. Rockwood and Green's fractures in adults. Philadelphia: Lippincott; 2001. p. 869-920.

33. Ring D, Rhim R, Carpenter C, et al. Isolated radial shaft fractures are more common than Galeazzi fractures. J Hand Surg [Am]. 2006;31(1):17-21.

34. Shoemaker SD, Comstock CP, Mubarak SJ, et al. Intramedullary Kirschner wire fixation of open or unstable forearm fractures in children. J Pediatr Orthop. 1999;19(3):329-37.

35. Tredwell SJ, Van Peteghem K, Clough M. Pattern of forearm fractures in children. J Pediatr Orthop. 1984;4(5):604-8. 
36. Vainionpaa $\mathrm{S}$, Bostman $\mathrm{O}$, Patiala $\mathrm{H}$, et al. Internal fixation of forearm fractures in children. Acta Orthop Scand. 1987;58 (2):121-3.

37. Walsh HP, McLaren CA, Owen R. Galeazzi fractures in children. J Bone Joint Surg Br. 1987;69(5):730-3.

38. Worlock P, Stower M. Fracture patterns in Nottingham children. J Pediatr Orthop. 1986;6(6):656-60.

39. Wurfel AM, Voigt A, Linke F, et al. New aspects in the treatment of complete and isolated diaphyseal fracture of the forearm in childhood. Unfallchirurgie. 1995;21(2):70-6.
40. Wyrsch B, Mencio GA, Green NE. Open reduction and internal fixation of pediatric forearm fractures. J Pediatr Orthop. 1996;16 (5):644-50.

41. Yung PSH, Lam CY, Ng BKW, et al. Percutaneous transphyseal intramedullary Kirschner wire pinning: A safe and effective procedure for treatment of displaced diaphyseal forearm fracture in children. J Pediatr Orthop. 2004;24(1):7-12.

42. Yung SH, Lam CY, Choi KY, et al. Percutaneous intramedullary Kirschner wiring for displaced diaphyseal forearm fractures in children. J Bone Joint Surg Br. 1998;80(1):91-4. 